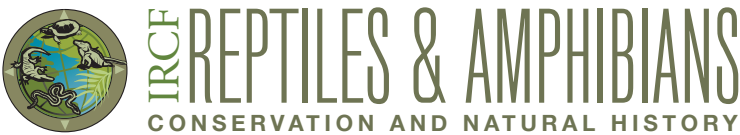

\section{Two Instances in South Australia of Sleepy Lizards, Tiliqua rugosa (Gray 1825), Feeding on Plant Species not Previously Recorded as Part of this Lizard's Diet}

\author{
Gerrut Norval ${ }^{1}$, Robert D. Sharrad ${ }^{1}$, and Michael G. Gardner ${ }^{1,2}$
}

${ }^{1}$ College of Science and Engineering, Flinders University, Adelaide, South Australia, Australia (norv0003@flinders.edu.au, robert.sharrad@flinders.edu.au) ${ }^{2}$ Evolutionary Biology Unit, South Australian Museum, North Terrace Adelaide 5000, South Australia, Australia (michael.gardner@flinders.edu.au)

\author{
Photographs by the senior author.
}

$\mathrm{T}$ he Sleepy Lizard (Tiliqua rugosa) is a large omnivorous skink that is endemic to southern Australia (Cogger 2014). These lizards usually feed on the leaves, flowers, and/or fruit of a variety of plants and will also opportunistically feed on invertebrates, small vertebrates, and carrion (Yeatman 1988; Henle 1990; Dubas and Bull 1991). Herein we describe two instances of adult Sleepy Lizards feeding on plants not previously recorded as part of their diet.

At 0945 h on 9 December 2018, the senior author observed a Sleepy Lizard on Salford Road, a dirt road in the Mid North Region of South Australia (33⒌'05"S, $139^{\circ} 13$ '23'E; $213 \mathrm{~m}$ asl; datum: WGS84). The lizard was next to a Wild Oat (Avena fatua) growing in the road and when the lizard gaped as a threat display, the inflorescence

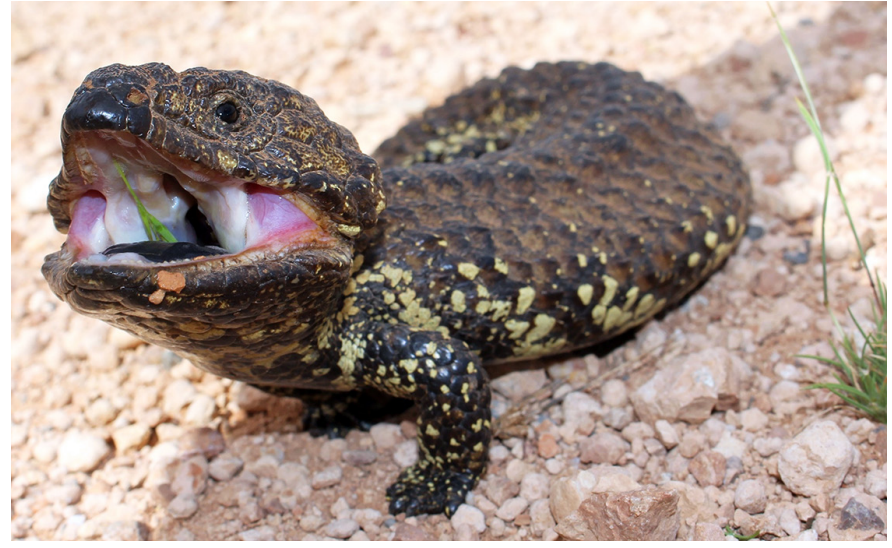

Fig. 1. A Sleepy Lizard (Tiliqua rugosa) found on 9 December 2018 eating the inflorescence of a Wild Oat (Avena fatua).

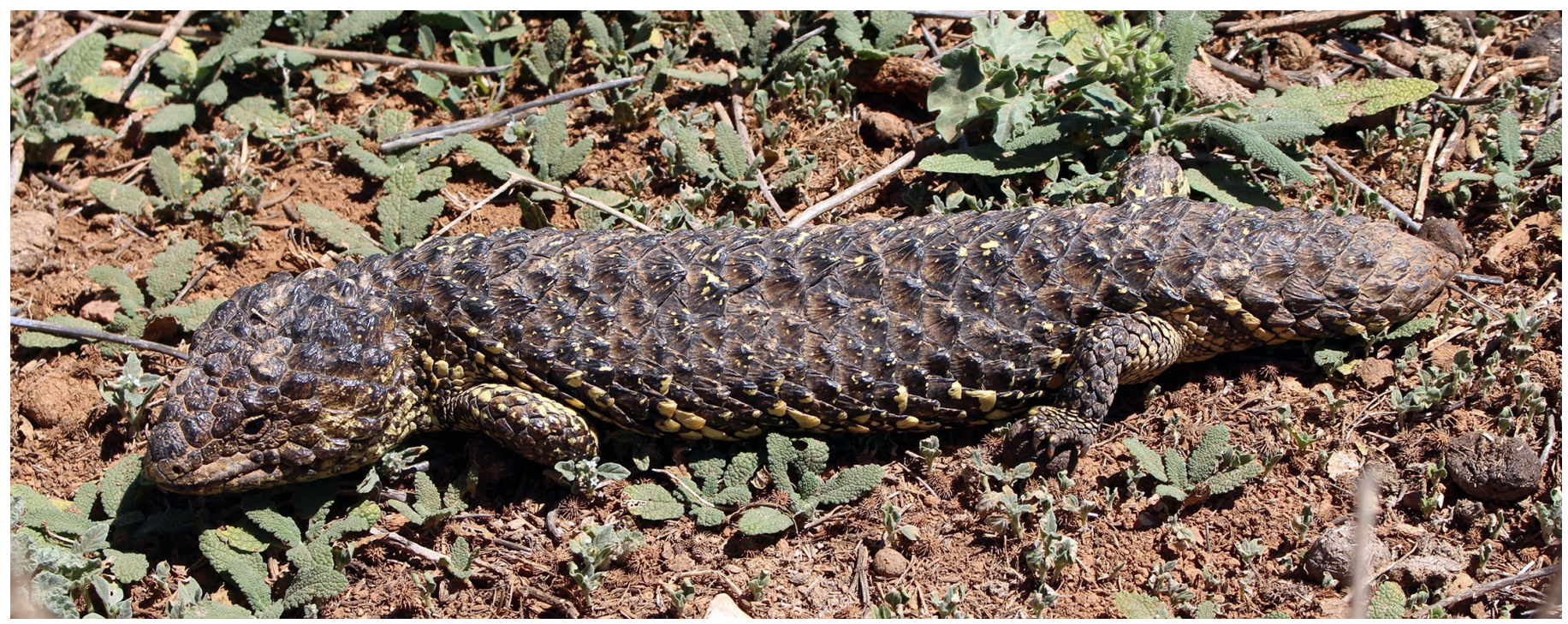

Fig. 2. A Sleepy Lizard (Tiliqua rugosa) found on the roadside on 23 December 2018 surrounded by Wild Sage (Salvia verbenaca), which is occasionally eaten by these lizards. 
and leaves of the grass were observed inside its mouth (Fig. 1). At $1115 \mathrm{~h}$ on 23 December 2018, the senior author noticed another T. rugosa on the roadside (Fig. 2) of the same dirt road but at a different locality $\left(33^{\circ} 54^{\prime} 47^{\prime \prime} \mathrm{S}, 139^{\circ} 18^{\prime} 35^{\prime \prime} \mathrm{E}\right.$; $161 \mathrm{~m}$ asl; datum: WGS84). While being handled, this lizard also gaped, and it had fragments of the leaves of Wards Weed (Carrichtera annua) and Stemless Thistle (Onopordum acaulon) in its mouth (Fig. 3). The senior author also observed

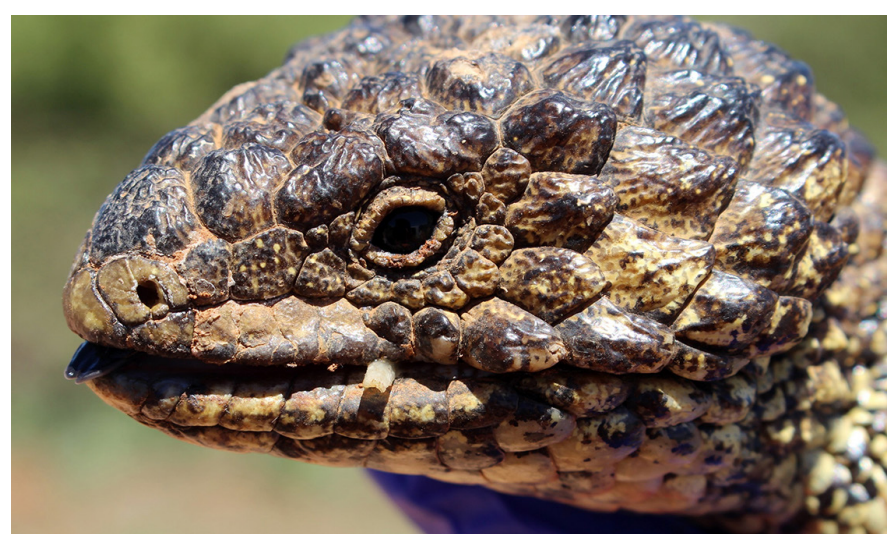

Fig. 3. Part of a Stemless Thistle (Onopordum acaulon) leaf is still protruding from the mouth of a Sleepy Lizard (Tiliqua rugosa) caught on 23 December 2018.

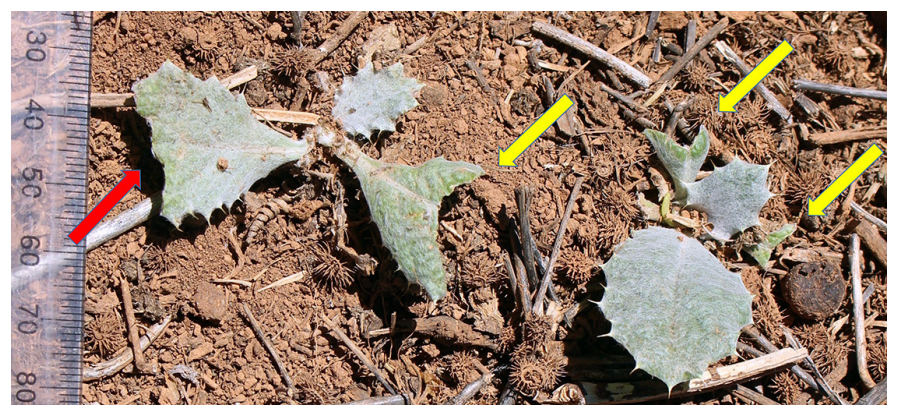

Fig. 4. Stemless Thistle (Onopordum acaulon) seedlings eaten by a Sleepy Lizard (Tiliqua rugosa) caught on 23 December 2018. The yellow arrows indicate fresh leaf damage where the lizard bit off parts of the leaves. The red arrow indicates old damage to a leaf, likely caused by a lizard on another day. signs of recent and past foraging in the vicinity of where the lizard was caught (Fig. 4).

To the best of our knowledge, neither $A$. fatua or $O$. acaulon have previously been recorded as part of the diet of $T$. rugosa. At the time of our observations, South Australia was experiencing a drought and plant species such as $C$. annua, which is commonly eaten by $T$. rugosa, were either absent or had stunted growth. Consequently, the lizards likely were feeding on plants that they would not usually eat due to a shortage of their preferred food. Our observations contribute to the list of species that are utilized as food. They also illustrate the importance of continued monitoring. For an omnivorous opportunistic species such as the Sleepy Lizard, observations throughout its range, in different seasons, and among seasons under different climatic conditions are required to have a thorough understanding of what plant species Sleepy Lizards exploit for food.

\section{Acknowledgements}

The observations above were made by the senior author while conducting field work as part of his doctoral research, which was partly funded in 2018 by grants from Friends of Private Bushland and the Royal Society of South Australia to Gerrut Norval. Clearance for the research were granted by the Animal Welfare Committee of Flinders University (No. E454/17) and the Department of Environment, Water and Natural Resources of the Government of South Australia (Permit No. A23436-26).

\section{Literature Cited}

Cogger, H.G. 2014. Reptiles and Amphibians of Australia. 7 ed. CSIRO Publishing, Collingwood, Victoria, Australia.

Dubas, G. and C.M. Bull. 1991. Diet choice and food availability in the omnivorous lizard, Trachydosaurus rugosus. Wildlife Research 18: 147-155.

Henle, K. 1990. Notes on the population ecology of the large herbivorous lizard, Trachydosaurus rugosus, in arid Australia. Journal of Herpetology 24: 100-103.

Yeatman, E.M. 1988. Resource partitioning by three congeneric species of skink (Tiliqua) in sympatry in South Australia. Unpublished Thesis, Flinders University, Adelaide, South Australia, Australia. 